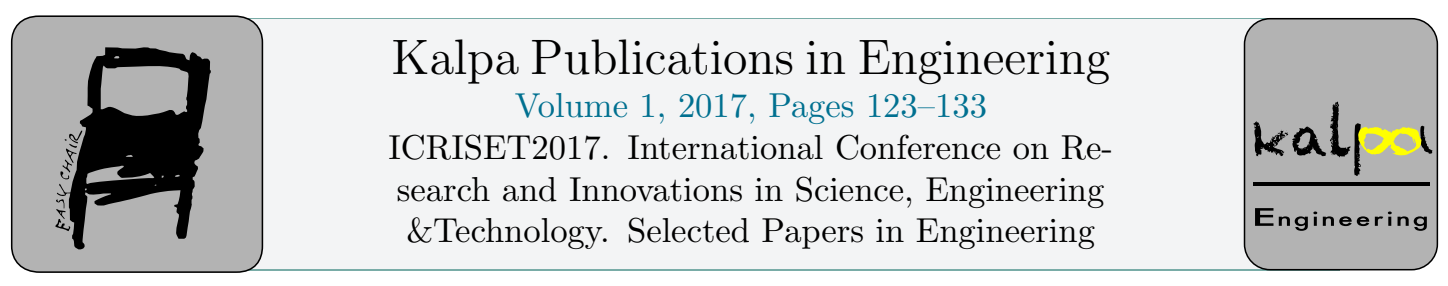

\title{
Application of SSSC-Damping Controller for Power System Stability Enhancement
}

\author{
Ankitkumar B Patel ${ }^{1}$ Pranav D Raval ${ }^{2}$ and Dhaval Patel ${ }^{1}$ \\ ${ }^{1}$ PG Student, Electrical Department \\ L E College \\ Morbi, India \\ ${ }^{2}$ Assistant Professor, Electrical Department \\ L E College \\ Morbi, India \\ ${ }^{2}$ University of Manchester, Manchester, U.K. \\ ankitpatel968@gmail.com, pranavraval13@yahoo.co.in, \\ dhavalpatel211093@gmail.com
}

\begin{abstract}
At present, power demand is increasing day by day so we have to transfer more power and for this we must have to improve stability limits of our power system. In this paper application of static synchronous series compensator (SSSC) for enhancement of power system stability is throughout investigated. SSSC is effectively utilized for power flow control in the power system. A SSSC-based damping controller is proposed for power oscillation damping and to improve the rotor angle stability. A improved control signal can be superimposed as a power flow control signal for SSSC damping controller to improve the rotor angle stability and power oscillation damping in system. Speed deviation of rotor is taken as the input signal to the SSSC damping controller. A single machine infinite bus system (SMIB) with SSSC is simulated in MATLAB/Simulink software. Simulation results shows the effectiveness of this controller for power system stability enhancement under different fault conditions.
\end{abstract}

Keywords-Static synchronous series compensator,Power oscillation, Damping controller, Rotor angle stability. 


\section{Introduction}

In recent years, advancement of power electronics makes feasible to use Flexible AC Transmission System (FACTS) in power system. FACTS controller are proficient for regulating the power system network very quickly so they are very useful for improvement of power system stability. Series capacitive compensation provide compensation of line impedance, which results in increment of the power transmission capacity of network, and thereby improve the power system stability. SSSC is a voltage source converter (VSC) based series compensator which provides the virtual compensation of line impedance. The capability of SSSC in operating both capacitive and inductive mode makes it very efficient in controlling the both active and reactive power [1-2]. Application of SSSC for rotor angle stability, voltage stability, power flow control and power system oscillation damping is found in several reference papers [3-5]. To eliminate the power oscillation in the power system an auxiliary signal can be superimposed as power flow control signal for SSSC controller. Use of power system stabilizers is also found for damping the electromechanical oscillations up to some extent. Controllers like power oscillation damping (POD), Proportional Integral (PI) and Proportional Integral Derivative (PID) are used for FACTS controllers.

In this paper we proposed simple Lead-Lag structure type damping controller for power system stability enhancement. Rotor Speed deviation and line active power can be used as input signal for controller as local and remote signal respectively [5]. Rotor speed deviation $(\Delta \omega)$ as a input signal gives better results in comparison with line active power so here we used $\Delta \omega$ as input signal to the damping controller. Proposed SSSC based damping controller is tested on single machine infinite bus system (SMIB) under several phase fault conditions in MATLAB Simulink software.

\section{System Model Under Study}

The single-machine infinite bus (SMIB) system as shown in Figure. 1 is considered under study in the paper. A single synchronous generator is connected to infinite bus through transformer (step-up) - SSSC and transmission lines are comprised in the system. In Figure. 1 ,

$\mathrm{V}_{\mathrm{S}}=$ Generator terminal voltage

$\mathrm{V}_{\mathrm{R}}=$ Infinite bus voltage

$\mathrm{V}_{1}=$ Bus 1 voltage

$\mathrm{V}_{2}=$ Bus 2 voltage

$\mathrm{V}_{\mathrm{DC}}=\mathrm{DC}$ voltage source

$\mathrm{V}_{\mathrm{cnv}}=$ Converter

output voltage

$\mathrm{P}_{\mathrm{L}}=$ Real power flow

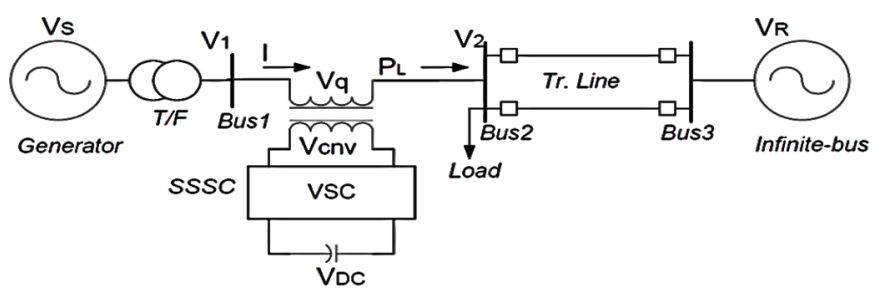

Fig. 1 Single-machine infinite bus system(SMIB) with SSSC[10]. 


\section{A. SSSC Configuration}

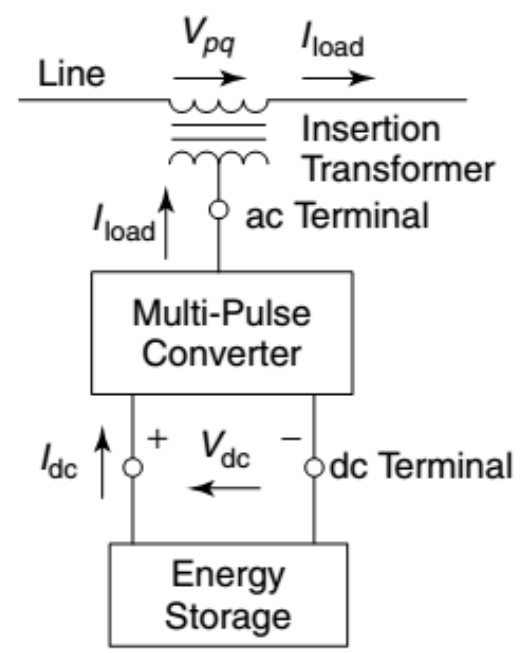

Figure. 2 SSSC basic configuration

SSSC is basically a solid state VSC attached in series to the transmission line and it generates the controllable $\mathrm{AC}$ voltages in quadrature to the line current. It provides virtual compensation of the line impedance by inserting the controllable voltage in the line which in turn control the amount of real power transmitted by the network [6-7]. By controlling the magnitude and polarity of injected voltage $\left(\mathrm{V}_{\mathrm{pq}}\right)$ we can control the compensation level. It can be operated in both inductive as well as capacitive mode as per power system requirement. With DC energy source like battery, SSSC is capable for injecting real power in the system. As a energy storage device we used DC link capacitor connected to DC side of the VSC. The VA rating of insertion transformer and converter of SSSC is depend on maximum line current $\left(\mathrm{I}_{\max }\right)$ and maximum injected voltage $\left(\mathrm{V}_{\mathrm{qmax}}\right)$.

B. Intenal Control Sysytem

The internal control diagram of SSSC is shown in Figure. 3 which comprises of:

- The PLL block used for synchronization purpose. It synchronizes on positive sequence component of line current (I). It is used to evaluate the direct axis 


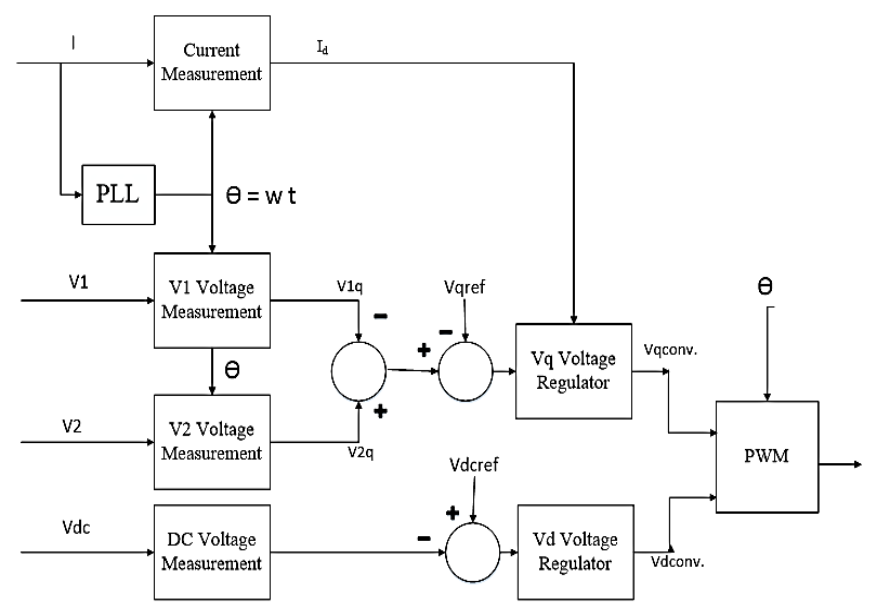

Figure. 3 Internal control diagram of SSSC.

component and quadrature axis component of the line current and voltage.

- Measurement system measures $V_{1 q}$ and $V_{2 q}$ which are the $q$ components of $V_{1}$ and $V_{2}$ respectively.

- $\mathrm{AC}$ voltage regulator calculate the $\mathrm{q}$ component of $\mathrm{V}_{\mathrm{qcnv}}$ and $\mathrm{DC}$ voltage regulator calculate the $\mathrm{d}$ component of $\mathrm{V}_{\mathrm{denv}}$.

Appropriate change in injected voltage $\left(\mathrm{V}_{\mathrm{q}}\right)$ is done using voltage source converter, which is connected, to the coupling transformer on secondary side. Converter consists of power semiconductor switches like IGBTs and GTOs. Here we use IGBT 6-pulse PWM inverter in this simulation work. In voltage, regulator block we used proportion Integrator (PI) controller and output of the PI controller is given to the PWM pulse generator. We have to convert the output of regulator block into abc component from dq component.

\section{Proposed Approach}

\subsection{Structure of Proposed Damping Controller}

A two stage lead-lag structure type controller shown in Figure. 4 is proposed as a SSSCbased damping controller to control the injected voltage Vq of SSSC in this paper. This structure is preferred by many utilities because it is easy for the online tuning and also for low assurance of the accuracy and stability by some tradition adaptive or variable structure methods. It processes the given input signal by consedering the reduction in peak overshoots and settling time of the signal.

This structure of damping controller as shown in Figure.4 mainly contains of four blocks: Delay block, Gain block, Washout block and two stage lead-lag block. Delay provided by delay block depends upon selection of the remote or local input signal. For the local input signal only sensor time delay is considered and for the remote signal sensor time as well as transmission time delay is also considered. 


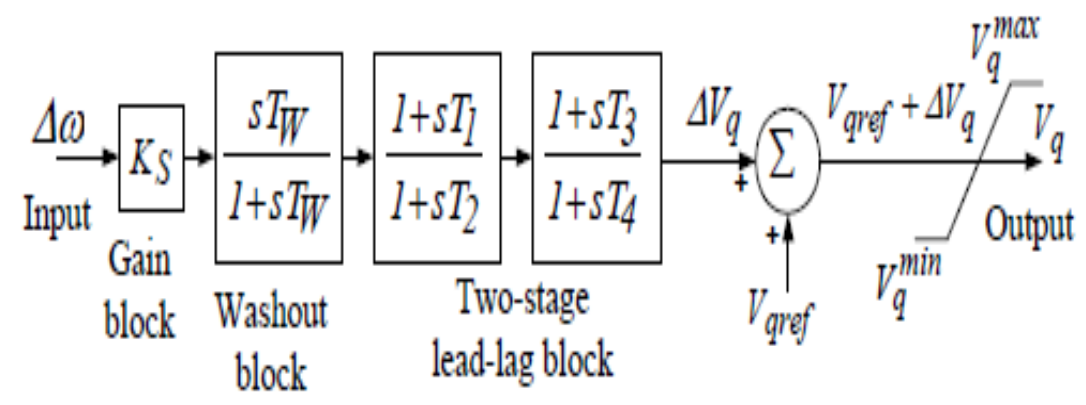

Figure. 4 Structure of propose lead-lag type damping controller

The washout block is used as the high pass (HP) filter. The value of washout time constant is taken high (1-20 s) in order to permit signals having high oscillations to pass unaffected to the next block [8]. Two stage lead-lag compensator block is used to adjust the phase lag between incoming and outgoing signals. $\mathrm{V}_{\text {qref }}$ is the desired reference value of the compensation voltage to be injected in transmission line under steady state condition. Resultant effective value of compensation voltage $\mathrm{V}_{\mathrm{q}}$ is obtained by adding the modulated voltage $\left(\Delta \mathrm{V}_{\mathrm{q}}\right)$ to the $\mathrm{V}_{\text {qref. }}$. This $\mathrm{V}_{\mathrm{q}}$ output signal from controller is given to the SSSC internal control System.

\subsection{Problem Formulation}

The value of washout time constant $\left(\mathrm{T}_{\mathrm{W}}\right)$ is usually pre-defined, here we take $\mathrm{T}_{\mathrm{W}}=10 \mathrm{~s}$ in this simulation work. The value of gain $\mathrm{K}_{\mathrm{s}}$ and controller time constants $\left(\mathrm{T}_{1}, \mathrm{~T}_{2}, \mathrm{~T}_{3}\right.$ and $\left.\mathrm{T}_{4}\right)$ are to be calculated. We calculated these parameters by trial and error method using some pre-specified values. Under steady state equilibrium conditions, value of $\mathrm{V}_{\mathrm{qref}}$ and $\Delta \mathrm{V}_{\mathrm{q}}$ remains constant. Under dynamic conditions, the value of $\mathrm{Vq}$ is changed to damp the power oscillation in system. In dynamic condition, effective value of injected voltage is given by,

$$
V_{q}=\Delta V_{q}+V_{q r e f}
$$

To design the effective damping controller, we have to select the proper input signal, which gives the desired control actions for our system. Line active power, bus voltage, line current, rotor angle deviation, and rotor speed deviation can be taken as input signal to the controller. Generally, line active power and line current are taken as local signal and as a remote signal rotor speed and angle deviation are taken. Here we used rotor speed deviation as a remote input signal for damping controller because it gives better results in comparison with line active power. Fiber optical communication, GPS system and wide area measurement system are very useful for practical application of transmitting this remote signal in real time. Here we selected $15-\mathrm{ms}$ time for sensor time delay and 50-ms for signal transmission delay for remote input signal in worst scenario of signal transmission system [9]. 


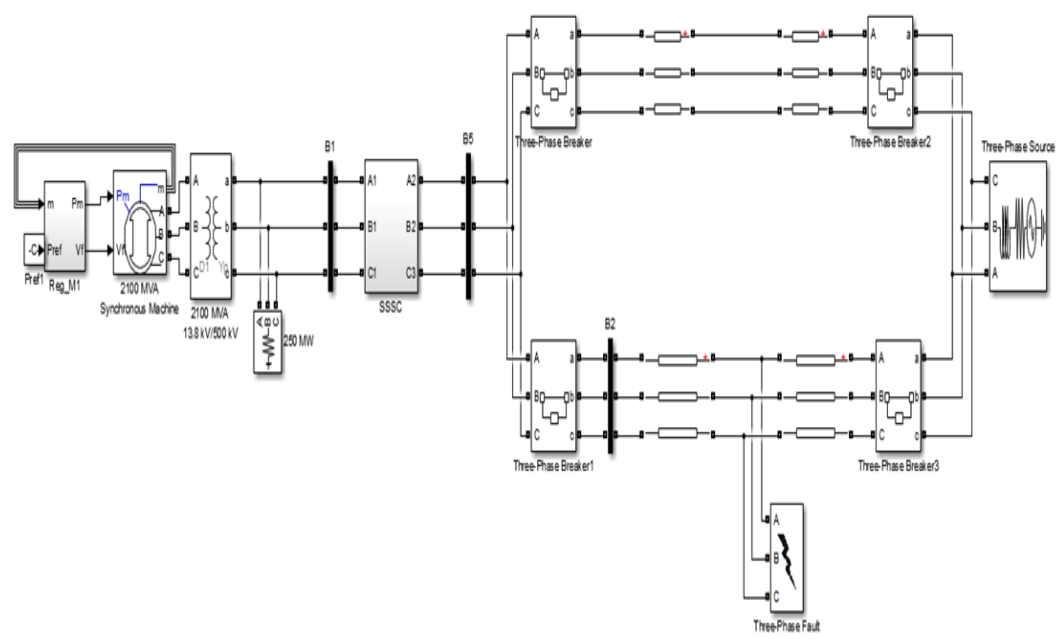

Figure. 5 Simulink model of SMIB system with SSSC.

\section{Simulation Test System Description}

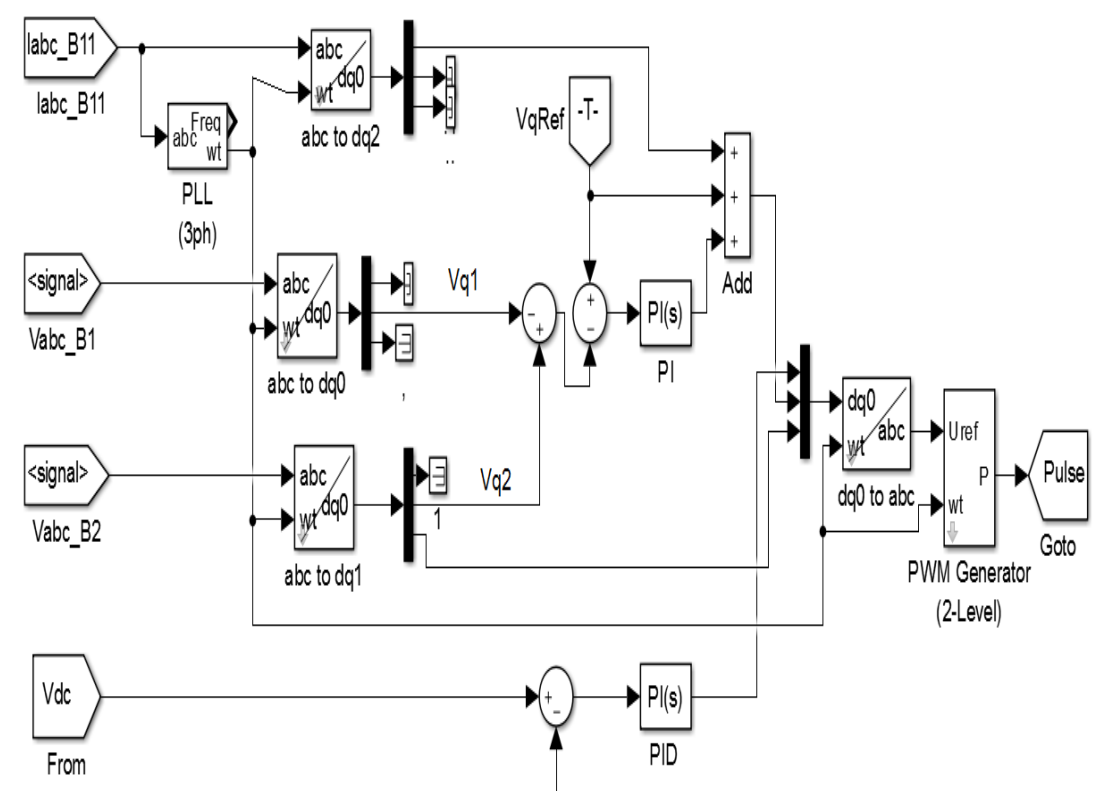

85000 Vdcref

Figure. 6 Internal control system of SSSC in MATLAB 
The single machine infinite bus system with SSSC, which is simulated in MATLAB is shown in Figure.5.The system comprises of a 2100 MVA synchronous generator followed by 2100 MVA step up transformer connected to the infinite bus through double circuit transmission line. The voltage of infinite bus is taken as $500 \mathrm{kV}$ and phase angle is $0^{\circ}$. A local load of $250 \mathrm{MW}$ is connected to the generator bus. For infinite bus we have used $500 \mathrm{kV}$ voltage source with 15000 MVA three phase short level. A three phase star/delta series connected transformer is used as insertion or coupling transformer for SSSC. The internal control system used to generate pules for converter IGBTs in MATLAB Simulink is shown in Figure. 6.

This system is tested under double line to ground (LLG) and 3-phase fault to ground (LLLG) at middle of the lower transmission line. Simulation results of various parameters of single machine infinite bus system are observed. Detailed parameters of the system are given in the Appendix.

\section{Simulation Results}

For analyzing our Simulink model for stability point of view, we created double line to ground and three phase to ground fault at time $\mathrm{t}=2$ second and after 5 cycles fault was cleared. Simulation results of rotor speed deviation, line active power flow and load angle with and without SSSC damping Controller under LLG and LLLG fault conditions are given below.

\subsection{Simulation Results For LLG Fault}

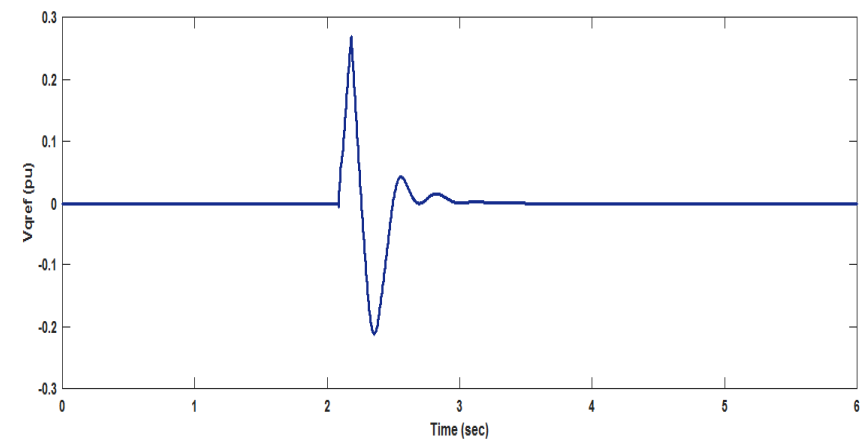

Figure. 7 Vqref signal for double line to ground fault to SSSC.

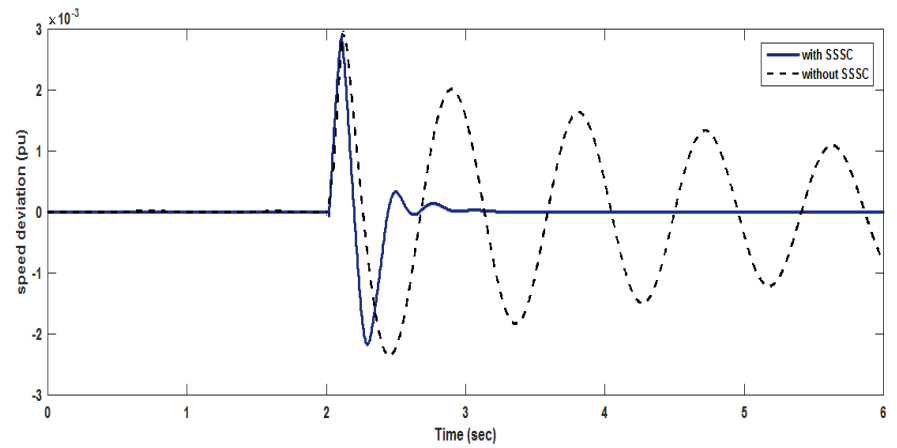

Figure. 8 Response of speed deviation under LLG fault condition. 


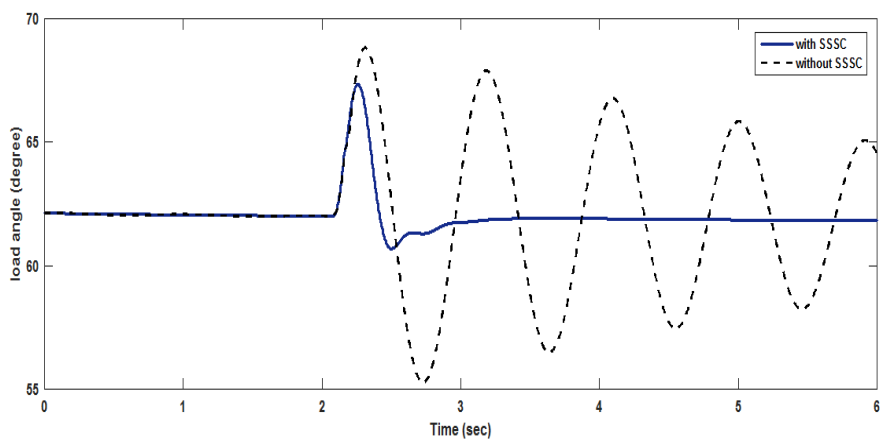

Figure. 9 Response of load angle under LLG fault condition.

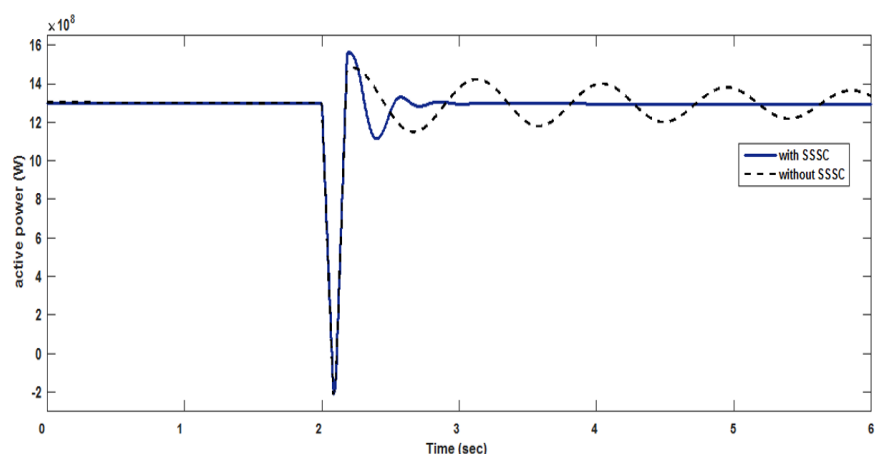

Figure. 10 Response of active power under LLG fault condition.

\subsection{Simulation Results For LLLG Fault}

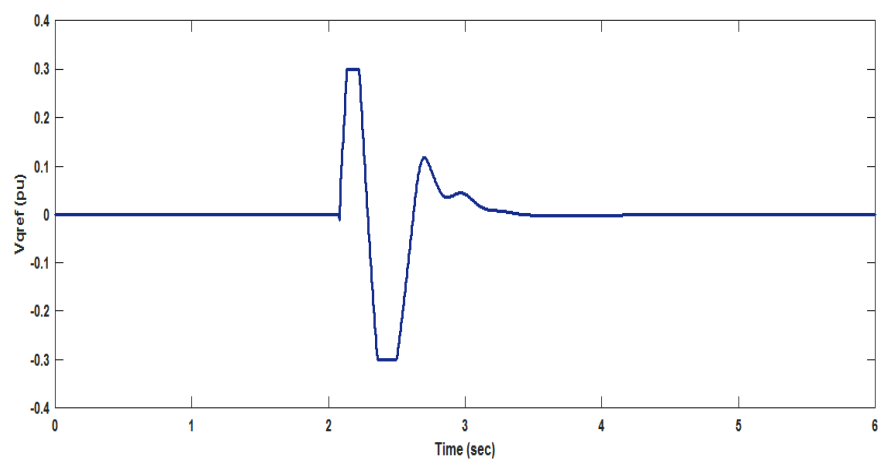

Figure. 11 Vqref signal for three phase fault (LLLG) to SSSC. 


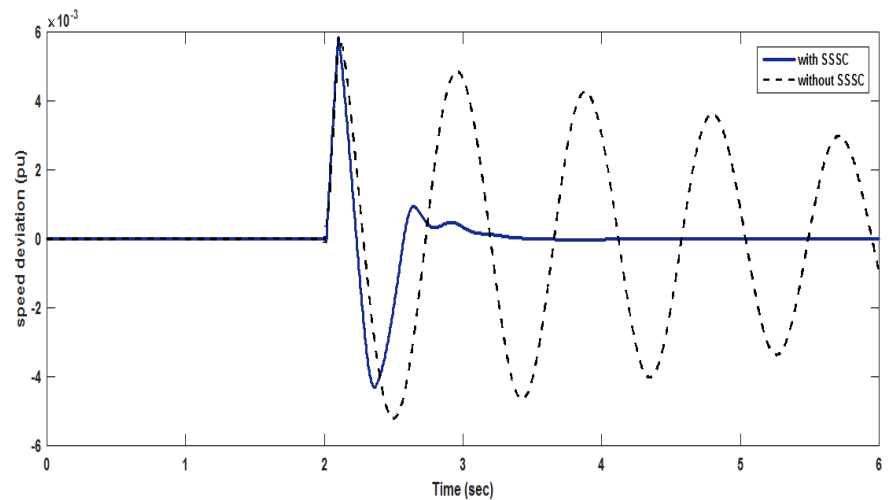

Figure. 12 Response of speed deviation for LLLG fault condition.

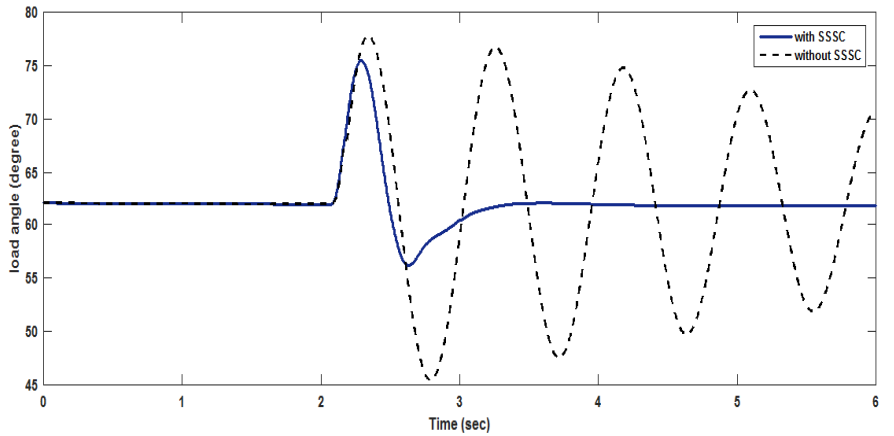

Figure. 13 Response of load angle for LLLG fault condition.

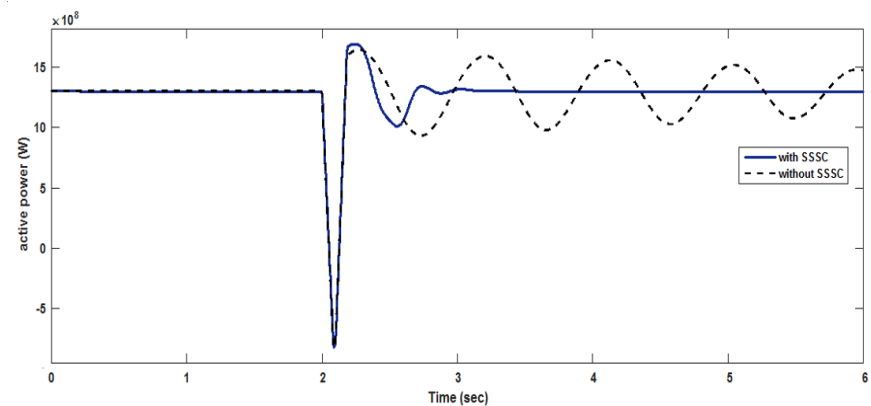

Figure. 14 Response of active power for LLLG fault condition. 


\section{Conclusion}

The capability of SSSC to work in both capacitive and inductive mode is very useful for rotor angle stability and power oscillation damping. The damping controller is proposed to give reference signal of injected voltage to SSSC in this paper. We simulate single machine infinite bus system with SSSC connected at generator bus side. Rotor speed deviation is taken as input for the damping controller. Simulation results under double line to ground fault and three phase fault conditions were observed. We can see that speed deviation and rotor angle settles down to original stable value with very short time period

(approximate within 0.5-1 second) after being subjected to LLG and LLLG faults. Power oscillations are also damped out very effectively. From simulation results we can say that the results obtained using SSSC damping Controller are much better than results obtained without SSSC. We can effectively improve rotor angle stability and damp power oscillations by using SSSC based Damping controller.

\section{ACKNOWLEGEMENT}

I gratefully acknowledge the guidance and support of my guide prof. P.D. Raval for this work. I would like to thank head of the electrical department prof. S.N. Pandya and my institute L. E. College, morbi for providing good environment. I would also like to thank my all classmates and friends for their encouragement.

\section{Appendix}

Simulation system data used in this study is given below [10].

1. Generator: $\mathrm{S}=2100 \mathrm{MVA}, \mathrm{V}=13.8 \mathrm{kV}, \mathrm{X}_{\mathrm{d}}=1.305 \mathrm{pu}, \mathrm{X}_{\mathrm{d}}{ }^{\prime}=0.296 \mathrm{pu}, \mathrm{X}_{\mathrm{d}}{ }^{\prime}{ }^{\prime}=0.252 \mathrm{pu}, \mathrm{X}_{1}=0.243$ $\mathrm{pu}, \mathrm{Xq}=0.474 \mathrm{pu}, \mathrm{Xq}{ }^{\prime}=0.243 \mathrm{pu}, \mathrm{H}=3.7^{\text {s. }}$

2. Transformer $\left(\mathrm{D}_{1} / \mathrm{Y}_{\mathrm{g}}\right)$ :

$\mathrm{S}=2100 \mathrm{MVA}, \mathrm{V}=13.8 / 500 \mathrm{kV}, \mathrm{R}=0.002 \mathrm{pu}, \mathrm{L}_{1}=0 \mathrm{pu}, \mathrm{L}_{0}=0.12 \mathrm{pu}$

3. Transmission line:

$1=300 \mathrm{~km}, \mathrm{R}_{1}=0.025 \mathrm{ohm} / \mathrm{km}, \mathrm{R}_{0}=0.3865 \mathrm{ohm} / \mathrm{km}, \mathrm{L}_{1}=0.933 \mathrm{mH} / \mathrm{km}, \mathrm{L}_{0}=4.126 \mathrm{mH} / \mathrm{km}$, $\mathrm{C}_{1}=12.74 \mathrm{nF} / \mathrm{km}, \mathrm{C}_{0}=7.74 \mathrm{nF} / \mathrm{km}$

4. $\mathrm{SSSC} /$ Insertion transformer:

$\mathrm{S}=180 \mathrm{MVA}, \mathrm{V}=50 / 50 \mathrm{kV}, \mathrm{V}_{\mathrm{DC}}=85 \mathrm{kV}, \mathrm{V}_{\text {dcref }}=90 \mathrm{KV}, \mathrm{C}_{\mathrm{dc}}=2.26 \mathrm{mF}$.

5. Damping Controller:

$\mathrm{K}=73.40, \mathrm{~T}_{\mathrm{w}}=10 \mathrm{~s}, \mathrm{~T}_{1}=0.336 \mathrm{~s}, \mathrm{~T}_{2}=0.225 \mathrm{~s}$, $\mathrm{T}_{3}=0.64 \mathrm{~s}, \mathrm{~T}_{4}=0.72 \mathrm{~s}$.

6. Load: $\mathrm{L}=250 \mathrm{MW}$. 


\section{REFERENCES}

[1] N. G. Hingorani and L. Gyugyi, Understanding FACTS, Concepts and Technology of Flexible AC Transmission Systems. Piscataway, NJ: IEEE Press, 2000.

[2] R. Mohan and R. K. Varma, Thyristor-Based FACTS Controllers for Electrical Transmission Systems. Piscataway, NJ: IEEE Press, 2002.

[3] H.F. Wang, Static synchronous series compensator to damp power system oscillatinos, Electr. Power Syst. Res. 54 (2000) 113-119

[4] Hamed Taheri ,Saeed Shahabi ,Shamsodin Taheri “ Application of Synchronous Static Series Compensator (SSSC) on enhancement of voltage stability and power oscillation damping" IEEE june 2009

[5] S. Panda, S.C. Swain ,P.K. Rautray, R.K. Malik, G. Panda, "Design and analysis of SSSC-based supplementary damping controller",Elsevier, Simulation Modelling Practice and Theory 18 (2010) 1199-1213

[6] L. Gyugyi, C.D. Schauder, K.K. Sen, "Static synchronous series compensator: a solid state approach to the series compensation of transmission lines", IEEE Trans. Power Delv. 12 (1997) 406-417

[7] K.K. Sen, SSSC-static synchronous series compensator: theory, modeling, and applications, IEEE Trans. Power Delv. 13 (1998) 241-246.

[8] P. Kundur, Power System Stability and Control, McGraw-Hill, New York, 1994.

[9] S. Ray, G.K. Venayagamoorthy, E.H. Watanabe, A computational approach to optimal damping controller design for a GCSC, IEEE Trans. Power Delv. 23(3) (2008) 1673-1681.

[10]Sidhartha Panda, N. P. Padhy , "A PSO-based SSSC Controller for Improvement of Transient Stability Performance" International Journal of Electrical, Computer, Energetic, Electronic and Communication Engineering Vol:1, No:9, 2007 